\title{
O órgão odorífero abdominal do macho de Caligo arisbe Hbn. (Lepidoptera, Brassolidae).
}

de

\author{
Rudolf Barth \\ (com 8 figuras)
}
A. Introdução
B. Observações morfológicas
C. Observações histológicas
D. Função
E. Resumo
F. Literatura

A. Introdução.

No caso que se encontram em espécies de um grupo de gêneros dos lepidópteros (família ou subfamília) nos machos glândulas odoríferas sexuais, pode-se tomar como regra que determinadas partes do corpo com certa constância servem, preferidamente, como portadores.

Nas Nymphalidae são as nervuras da parte superior da asa nas quais nas Nymphalinae são encontradas saliências odoríferas ou sulcos odoríferos abertros, nas Heliconiinae filas de covas odoríferas. Os machos das Pieridae com escamas odoríferas possuem-nas em filas entre as escamas de coloração das partes superiores das asas. Das Hesperidae as Heeperiinae têm escamas odoríferas em saliências do metatórax e um pincel-distribuidor nas tíbias posteriores e ainda no espaço costal da asa anterior uma dobra que inclue um aparelho odorífero. As Pamphilinae possuem um sulco odorífero na parte central da asa anterior e as Pyrrhopyginae placas do metatórax com escamas odoríferas e com isto combinado um pincel-distribuidor nas tíbias das pernas posteriores. Os órgãos odoríferos dos machos do grupo "Aristolochienfalter" das Papilionidae aparecem numa dobra da margem posterior da asa posterior. No grupo de Ascanius o órgão representa um fêltro de lã branca como aparelho de evaporação enquanto êste falta no grupo de Polydamus. Esta regra pode ser provada por inúmeros outros exemplos. 
A formação do órgão em particular varia com intensidade maior ou menor. Encontra-se diferenças na forma das escamas ou cerdas odoríferas, na formação de evaporação, na extensão dos órgãos e na modalidade dos aparelhos portadores. Sempre pode-se observar das espécies de um grupo uma linha que conduz do grau mais baixo ao mais elevado de evolução o que indica que as respectivas espécies genèticamente pertencem uma à outra . Por êste método poderá assim em certos casos a observação dos órgãos odoríferos contribuir de esclarecer ligações de parentesco ou impedir a descrição inútil de subespécies duvidosas pois sempre encontram-se formações específicas para cada espécie.

Esta regra citada aplica-se também à família das Brassolidae. Com exclusão de outros campos glandulares hipodermais nas espécies de Opsiphanes podem-se encontrar em diversos gêneros desta família glândulas odoríferas cuja excreção poderá ser notado pelo órgão olfativo do homem, com placas de glândulas fechadas nas partes pleurais do $4 .^{\circ}$ e $5 .^{\circ}$ segmento abdominal as quais pertence ainda na parte anal da asa posterior um aparelho evaporador mais ou menos bem desenvolvido. Este órgão já foi descrito para as espécies de Opsiphanes (JuRRIAANSE, EltringhaM, BARTh) . Da mesma forma Brassolis astyra possue nesta localização numa formação simples e Caligo arisbe numa forma mais desenvolvida placas glanduiares. Enquanto encontra-se na Opsiphanes nas asas posteriores e nos tergitos do abdomen ainda glândulas auxiliares hipodermais, Brassolis astyra e Caligo arisbe apresentam apenas as citadas placas glandulares. No contrário à Opsiphanes o aparelho evaporador especialisado na parte anal da asa posterior é pouco desenvolvido em Caligo arisbe enquanto êle parece ausente totalmente em Brassolis astyra.

Em seguida é apresentado o órgão odorífero do macho do Caligo arisbe interessando aqui principalmente a forma e a estrutura das escamas odoríferas, a histologia da célula glandular e o mecanismo da inserção móvel das escamas odoríferas. Correspondendo ao estado fisiológico do exemplar a escama pode deslisar para fora ou para dentro como isto já foi descrito para Opsiphanes (BARTH, 1952). O caminho que conduz à esta finalidade no Caligo é tão diferente das condições correspondentes no Opsiphanes que a descrição do órgão de Caligo que conforme nosso conhecimento não foi estudado ainda, representa um enrequecimento dos nossos conhecimentos sôbre as múltiplas possibilidades do plano de estrutura aparentemente rígido do corpo do inseto.

\section{B. Observações morfológicas.}

Trata-se nêste órgão odorífero de um órgão composto constante das placas glandulares do abdomen e de um aparelho auxiliar para a evaporação da secreção nas asas posteriores. 
As placas glandulares (fig. 1) estão situadas nas partes pleurais do $4 .^{\circ}$ e $5 .^{\circ}$ segmento abdominal. As medidas referem-se a um macho com as seguintes medidas da asa anterior:

Comprimento da articulação da asa até o fim de $R_{4}: 5,9 \mathrm{~cm}$, comprimento da articulação da asa até o fim de $\mathrm{An}_{1}: 3,9 \mathrm{~cm}$, comprimento do fim de $R_{4}$ até o fim de $\mathrm{An}_{1}: 4,2 \mathrm{~cm}$.

Ambas as placas de glândulas quando vistas de cima são quase uniformemente ovais. A maior no $4 .^{\circ}$ segmento tem os diâmetros de 2,81 $\mathrm{mm}$ e de $1,90 \mathrm{~mm}$, a menor no $5 .^{\circ}$ segmento de $1,98 \mathrm{~mm}$ e $1,72 \mathrm{~mm}$. A primeira está na sua extensão total na área do $4 .^{\circ}$ segmento, a última porém sòmente na parte anterior do $5 .^{\circ}$ segmento, urna grande parte (quando em repouso é a parte anterior da placa) está na membrana intersegmental entre o $4 .^{\circ}$ e $5 .^{\circ}$ segmento e só é visível de fora num caso de extensão máxima do corpo. Ambas as placas são incluídas por diversas filas de saliências finas em forma de anel $(F)$ e apresentam uma separação nítida das partes hipodermais vizinhas e nuas. A cutícula das placas está coberta densamente com escamas odoríferas encostadas firmemente à área. O plano de inserção (fig. 2) mostra exclusivamente copos grandes de inserção com diâmetros de 20 micra a 25 micra os quais observam uma distância de 40 micra a 50 micra (medidas do centro ao centro). Em cada $1 \mathrm{~mm}^{2}$ estão em média 500 inserções. Todas as quatro placas juntas têm uma superfície de quase 16,59 mm² devendo-se contar com 8200 a 8400 escamas odoríferas.

As escamas odoríferas são escamas ligítimas (fig. 3) cuja lamela superior tem estrias enquanto a sua lamela inferior consta apenas de uma membrana (fig. $3 \mathrm{UL}$ ). Entre as estrias muito finas das quais correspondem apenas 25 numa largura de escama de 100 micra, não existem conetivas. O espaço entre elas consta de uma membrana extremamente fina $(M)$ que mostra nem poros nem perfurações e parece ser completamente homogênea. Entre ambas ás lamelas não existem trabéculas, o lume é completamente vazio servindo à secreção da glândula como depósito. Esta suposição é confirmada pela observação que a escama sêca forma numerosas dobras (fig. 3 a, F), que porém no animal vivo as escamas são estendidas em forma de uma vesícula e apresentam sempre um brilho húmido. A ausência do sistema de apôio na escama é um achado significativo. Escamas recentemente levadas numa lâmina e cobertas com uma lamínula arrebentam e em redor delas forma-se uma mancha de líquido íncolor. Num espaço de ar fechado é possível de cristalizar o líquido: Colocam-se na cova de uma lâmina cavada escamas frescas (20 a 50), a margem da cova é fechada com um anel de bálsamo de canadá a qual deitam-se a lamínula de forma que o espaço está hermèticamente fechado. Depois de algumas horas a lâmina é colocada por 2 a 3 horas na estufa a $60^{\circ}$. Aqui evapora fortemente o líquido. Em seguida refrescam-se primeiro a $40^{\circ}$ e depois em temperatura ambiente. Nisto uma parte de líquido evaporado 
sublima para cristais típicas e combinações cristalinas (fig. 5). Não é possível de concluir si se trata nêstes cristais do material aromático ou de resíduos.

A forma da escama é comprido-retangular, a ponta larga. A base é modificada pela inserção especialisada. Quase 50 micra da parte basal são separadas por um estreitamento de uma largura de 10 a 15 micra do corpo da escama. Esta parte é alargada em direção à base (BA) e em forma de funil (TR). A margem basal é irregular apresentando aumentos e anexos que podem medir a 30 micra. Os anexos não têm estrias. A função destas formações marginais deve ser a mesma como aquela descrita para as escamas odoríferas das Heliconiinae, i. é de fixar a escama na sua posição na área da asa (BARTH, 1952). Da margem basal a parede penetra em forma de cone no funil até o estreitamento e o pedúnculo (ST) começa sòmente na profundidade do cone. Detalhes veja mais em baixo. A escama tem um comprimento total de 260 a 280 micra, a largura varia de acôrdo com o grau de formação das dobras entre 50 e 90 micras.

O aparelho auxiliar na asa posterior (fig. 6) consta de 4 filas de cerdas rígidas e de côr marrom (fig. 6 e 7) localisadas numa parte núa da área da asa. Esta parte está encostada quando em repouso aos lados abdominais com as placas das glândulas numa forma côncava. A área núa é circundada de um têreno de cerdas compridas (BOR). Si essas cerdas servem também como distribuidor do material aromático não está claro. As filas das cerdas estão imeditamente após a primeira nervura anal $\left(\mathrm{An}_{1}\right)$, no final do primeiro quarto do comprimento desta nervura. Elas são circundadas por uma área de cutícula nua e lisa que acompanha o primeiro têrço de nervura (em fig. 6 apontilhado) e tem um comprimento de quase $12 \mathrm{~mm}$ e uma largura de 5 a $6 \mathrm{~mm}$. $A \mathrm{An}_{1}$ nesta altura é mais fina e curvada para baixo de forma que a área nua forma uma cavidade plana em cujo centro encontra-se as filas das cerdas. Através da cavidade as cerdas quando em repouso estão encostadas à área da asa, quando a asa é estendida fortemente esta cavidade desaparece, as inserções são levantadas e com isto as cerdas colocadas quase verticalmente à área da asa. O efeito do aparelho auxiliar deve ser que a formação das cerdas retire a secreção das placas glandulares pelo efeito capilar com as asas recolhidas.

Daqui a secreção deve espalhar-se na área nua quando as cerdas são levantadas e abertas pois nêste momento acaba o efeito capilar. A observação dêste ponto no animal vivo mostra na área nua um brilho de humidade. Retirando cuidadosamente êste pedaço da área da asa pode-se sentir aqui o mesmo cheiro típico como nas placas glandulares separadas. A qualidade aromática deve-se designar como doce com gosto de sabão e é classificado pelos observadores em parte como agradável em parte como desagradável. Si as cerdas também como pincel-distribuidor deixam evaporar direitamente uma parte de secreção, deve-se considerar a sua finalidade principal de transportar a secreção das placas glandulares às áreas evaporantes. Pela distribuição 
em filas o seu efeito capilar é aumentado. Dados sôbre as medidas resultam da seguinte tabela:

\begin{tabular}{|c|c|c|c|c|c|}
\hline $\begin{array}{c}\text { Número } \\
\text { da } \\
\text { fila }\end{array}$ & $\begin{array}{l}\text { Número } \\
\text { das } \\
\text { cerdas }\end{array}$ & $\begin{array}{c}\text { Comprimento } \\
\text { das filas } \\
\text { em micra }\end{array}$ & $\begin{array}{l}\text { Comprimento } \\
\text { em média } \\
\text { das cerdas } \\
\text { em mm }\end{array}$ & $\begin{array}{l}\text { Distância } \\
\text { da analis } \\
\text { em micra }\end{array}$ & $\begin{array}{l}\text { Distância } \\
\text { entre } \\
\text { as filas } \\
\text { em micra }\end{array}$ \\
\hline 1 & 15 & 450 & 1,6 & 375 & \multirow{2}{*}{450} \\
\hline 2 & 30 & 530 & 1,8 & 315 & \\
\hline 3 & 45 & 750 & 2,1 & 210 & 500 \\
\hline 4 & 40 & 660 & 1,9 & 270 & 375 \\
\hline
\end{tabular}

\section{Observações histológicas.}

A hipoderme das placas glandulares consta exclusivamente de células glandulares às quais pertence cada vez uma célula de anel basal e degenerada. As células glandulares têm uma forma cúbica até prismática com uma largura de 35 a 50 micra e com uma altura de 50 a 80 micra. As medidas modificam-se com o estado fisiológico. No centro da área apical da glândula insere-se a escama odorífera. Em redor da inserção complicada (I) o conteudo da célula forma uma parte bem separada e em forma de cone com distribuição do plasma em forma dos raios (SF). Esstes raios são dirigidos para a abertura interna da inserção. A massa principal do plasma da célula está em redor do grande núcleo localisado quase no centro da célula formando um elipsóide com diâmetros de 15 a 20 e 30 a 35 micra. O eixo mais comprido está paralelo à membrana basal. Frenqüentemente a margem basal do núcleo tem ampliações irregulares (fig. 8).

A cromatina do núcleo é fôfa constando depois da fixação com ácido ósmico e coloração com hematoxilina férrica de grânulos de diversos tamanhos apoiados por uma rêde de cromatina. O plasma da zona central perto do núcleo é conforme o estado de secreção da célula denso e compacto ou cheio de vacúolos também de vários tamanhos dos quais encontram-se os maiores na margem da figura dos raios. Desta zona separa-se nitidamente uma camada basal (bem clara depois da fixação de Carnoy) cuja plasma tem uma estrutura fibrilosa lembrando por seu aspecto ao ergastoplasma (ER) das células do pâncreas. As estriações estão verticais na membrana basal (BM). Entre as estriações podem ser diferenciadas em grande número e tama- 
nho respeitável mitocóndrias (plastósomos) (PL) que constam de fios e ganchos granulados e estão colocados paralelamente às estriações ergastoplasmáticas.

Entre duas células glandulares vizinhas estão situadas apicalmente e com regularidade células degeneradas que devem ser consideradas como células de anéis basais (BZ) cujo plasma denso aproxima-se em cortes ótimos ao ângulo interno da inserção.

A inserção forma um copo de inserção largo (IB) que tem apenas um canal (I) curto e de lume grande. A parede do canal torna-se mais fina para o lado interno enquanto a endocuticula que corresponde normalmente a um têrço até um quarto da cutícula, termina e a exocutícula passa a ser muito fina. A exocutícula em forma de lamelas forma no fim do canal um aumento em forma de vesícula (KU) que penetra profundamente na célula apresentando no pólo basal uma grande abertura. Ao encontro desta quitinosa vesícula vão as estriações da figura plasmática dos raios (SF). Da margem externa do copo da inserção nasce formado sòmente pela camada externa da exocutícula, um cone quitinoso (CK) cuja superficie na ponta é virada para dentro e percorre daqui como túbulo fino com parede extremamente fina (abaixo de 0,2 micra) pelo centro o lume da inserção (RO). Na altura do canal de inserção o túbulo tem um aumento longitudinal. No seu fim êle vira para dentro passando para o pedúnculo da escama que agora de novo passa pelo túbulo ampliando-se no seu aumento também passando na ponta pela abertura do cone quitinoso para fora (SD). Nêste ponto o pedúnculo passa para a invaginação em forma de funil da parte basal da escama odorífera (TR) que de novo recebe o cone quitinoso da inserção. É um ótimo exemplo de constatar nêste objeto a continuidade da cutícula na parede do corpo do inseto e de observar que também formações complicadas são sempre o produto de evaginações e invaginações. E interessante que sempre na base do aumento do pedúnculo encontra-se uma massa irregular de uma substância não identificada que é tão grande que não pode penetrar na parte basal do pedúnculo.

\section{Função.}

Como no Opsiphanes (BARTH, 1952) a inserção da escama odorífera é móvel tendo sido alcançado porém aqui a mesma finalidade por outro caminho. No caso de aumento de pressão da secreção o espaço interno da inserção enche-se com secreção a qual após tratamento com ósmio é visível. Se dando a mais pressão o pedúnculo sai do cone quitinoso da inserção até o aumento em forma de vesícula é apertado no cone quitinoso que torna-se mais estreito. Desta forma a abertura basal do pedúnculo é levantada do plasma da figura dos raios à qual encosta-se, quando em repouso, e a secreção poderá sair pelo pedúnculo até ficar cheio o espaço da escama e a invaginação basal da escama si ter aberta. Assim a pressão na parede da escama é igual a pressão da secreção. A perda de secreção devido a passagem pelas partes membra- 
nosas da escama é compensada pela pressão da secreção. Um refluxo da secreção é impedido pela massa irregular acima citada na base do aumento em forma de vesícula. No final do período de secreção a base do pedúnculo vai novamente contra o plasma celular. Desta forma consegue-se uma emissão ao choque da secreção, uma vantagem de estímulo fisiológico ao contrário da emissão permanente da secreção em órgãos odoríferos mais primitivos.

E. Resumo.

1. O órgão odorífero do macho de Caligo arisbe é descrito morfológica e histològicamente.

2. O órgão consta de pares de placas glandulares de hipoderme com escamas odoríferas no quarto e quinto segmento do abdomen e de um aparelho auxiliar na asa posterior para a evaporação da secreção.

3. O aparelho auxiliar consta de 4 filas de cerdas e de uma área nua de evaporação com uma área em forma de anel com cerdas compridas.

4. Devido a falta de trabéculas as escamas odoríferas podem ser aumentadas em forma de vesícula.

5. O exame histológico demonstra nas células glandulares a presença de ergastoplasma e plastósomos grandes no pólo basal da célula.

6. A inserção é especialisada em alto grau. O pedúnculo da escama tem uma situação móvel o que facilita uma emissão da secreção em choque.

F. Literatura.

(veja parte alemã) 


\section{FIGURAS}

Fig. 1: a) $2 .^{\circ}$ a $50^{\circ}$ segmento abajominal (IIa-Va), lado direito do corpo. Pontilhado: área cuticular nua. As placas glandulares são situadas no $4 .^{\circ} \mathrm{e}$ $5 .^{\circ}$ segmento, no $5 .^{\circ}$ segmento a parte anterior da placa é situada na membrana intersegmental e é visivel sòmente no abdomen extremamente estendido.

b) Corte longitudinal esquemático pelos lados do $3 .^{\circ}$ até $5 .^{\circ}$ segmento abdominal (correspondendo com a seta A em fig. 1 a). IIIa-Va: $30^{\circ}$ a $5 .^{\circ}$ segmento abdominal, DPI e DPII: primeira e segunda placa glandular, DS: escamas odoriferas, $\mathrm{F}$ : dobras, IM: membrana intersegmental.

Fig. 2: Esquema da inserção das escamas nas placas glandulares (área: $0,25 \mathrm{~mm}^{2}$ ). Encontram-se sòmente grandes copos de inserção das escamas odoríferas.

Abb. 1: a) 2. bis 5. Abdominalsegment (IIa-Va), rechte Koerperseite. Punktiert: nackte Hautflaeche. Im 4. und 5. Segment liegen die Druesenplatten, im 5. Segment ist der vordere Teil der Platte auf der Intersegmentalmembran gelegen und nur bei uebernormal gestrecktem Abdomen sichtbar.

b) Schematischer Laengsschnitt durch die Seiten vom 3. bis 5. Abdominalsegment (entsprechend dem Pfeil $A$ in Abb. 1. a) IIIa-Va: 3. bis 5. Abdominalsegment, DPI und DPII: 1. und 2. Druesenplatte, DS: Duftschuppen, F: Falten, IM: Intersegmentalmembran.

Abb. 2: Insertionsplan der Druesenplatten (Flaecheninhalt $0,25 \mathrm{~mm}^{2}$ ). Es finden sich nur grosse Insertionsbecher von Duftschuppen. 


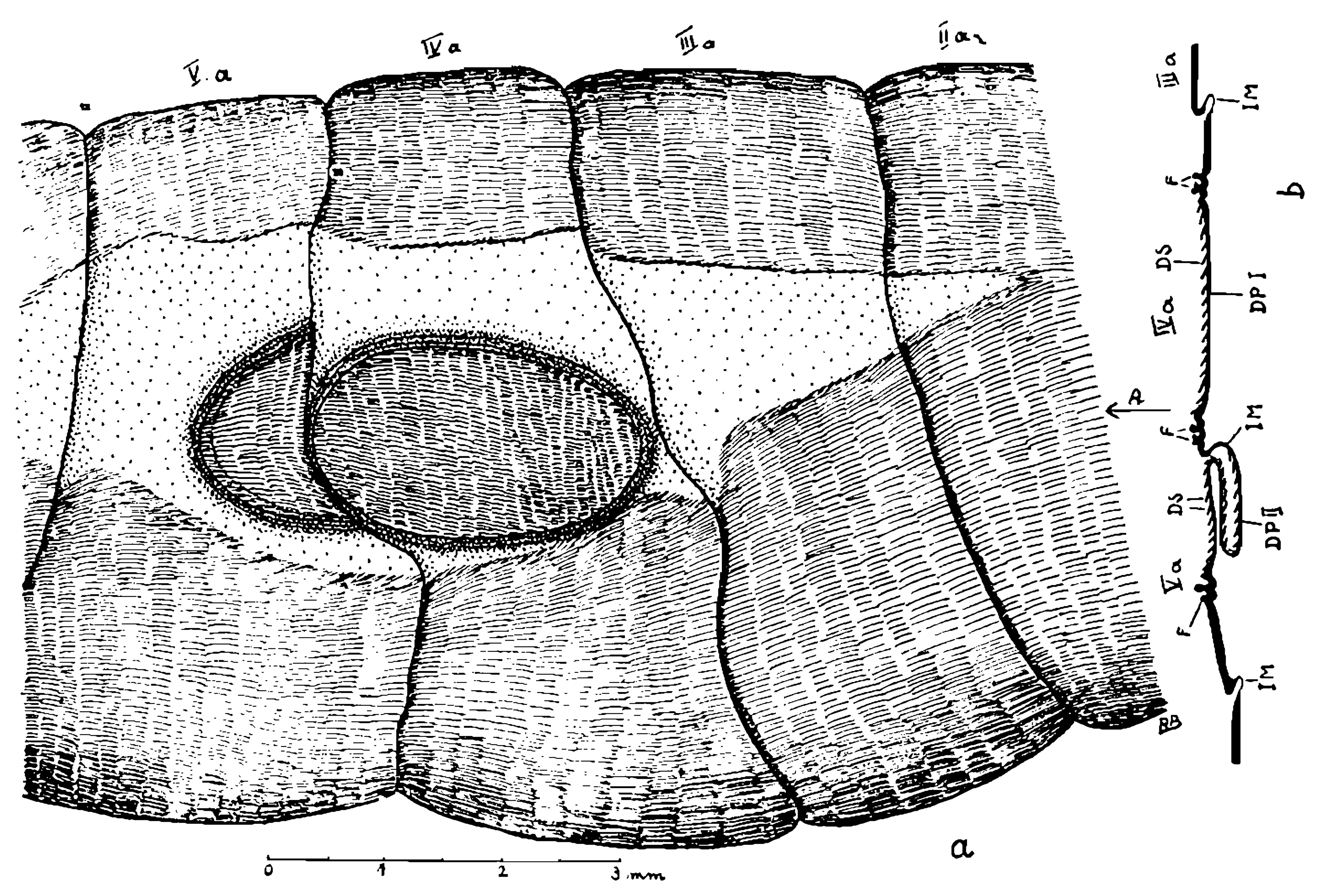

Fig. 1

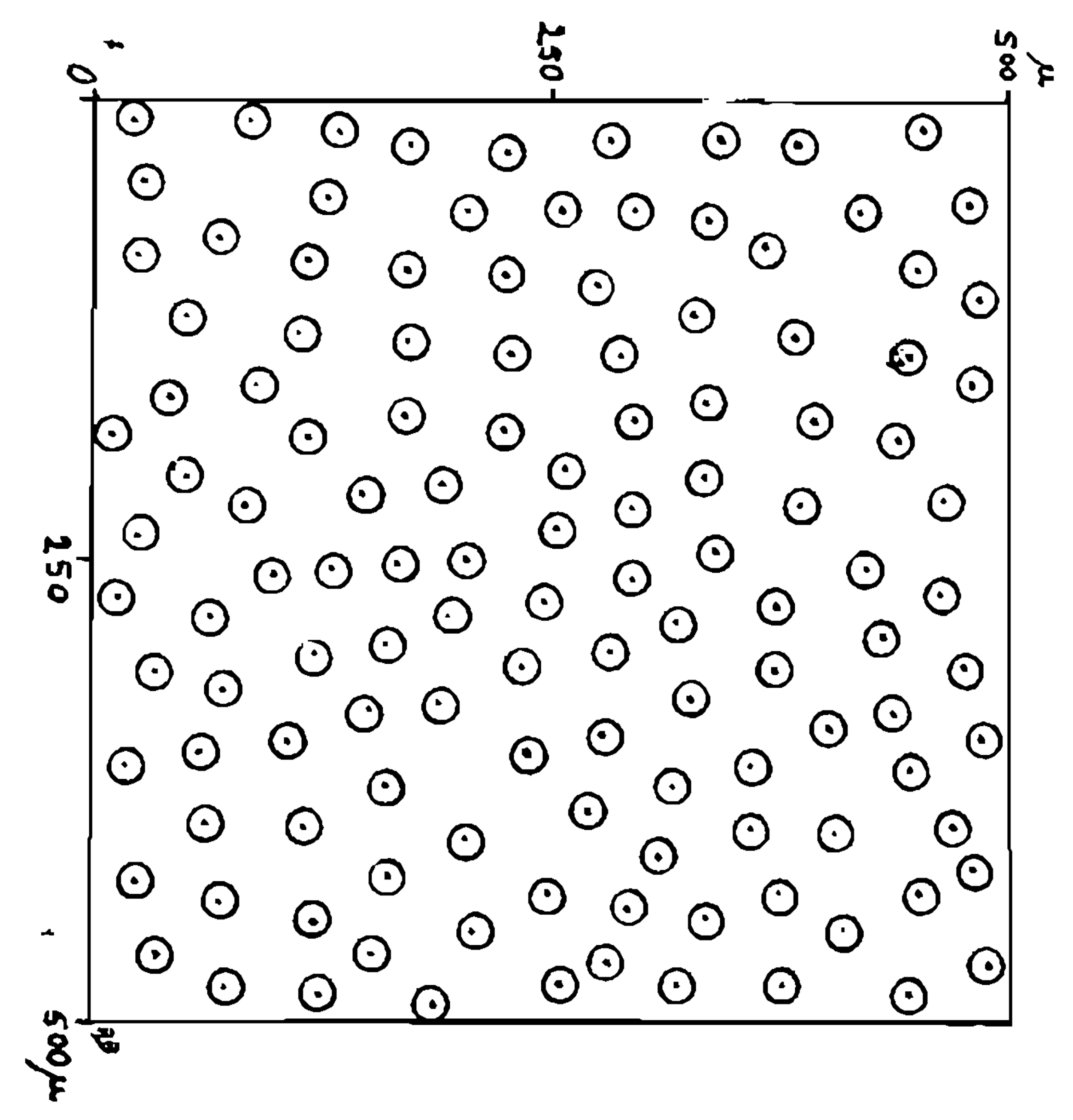

Fig. 2 
Fig. 3: a) escama odorifera, b) e c) margens basais das escamas odoríferas, d) corte transversal pela uma escama odorífera. BA: parte basal, EI: estreitamento, F: dobras, $\mathbf{M}$ : membrana, $\mathrm{RI}$ : estrias, $\mathrm{RI}_{1}$ : estrias sôbresalentes, ST: pedúnculo, TR: invaginação coniforme, UL: lamela inferior, $\mathrm{Z}$ : anexos da base da escama.

Fig. 4: Esquema tridimensional do corpo da escama odorífera. M: membrana, RI: estrias.

Abb. 3: a) Duftschuppe, b) und c) Basalraender der Duftschuppen, d) Querschnitt durch eine Duftschuppe. BA: Basalteil, EI: Einschnuerung, F: Falten, $\mathrm{M}$ : Membran, RI: Rippen, $\mathbf{R I}_{1}$ : ueberagende Rippen, $\mathrm{ST}$ : Stiel, TR: trichterfoermige Einstuelpung, UL: Unterlamelle, Z: Anhaenge der Schuppenbasis.

Abb. 4: Blockdiagramm aus dem Koerper der Duftschuppe. M: Membran, RI: Rippen. 
Mem. Inst. Oswaldo Cruz

Tomo 51, 1953

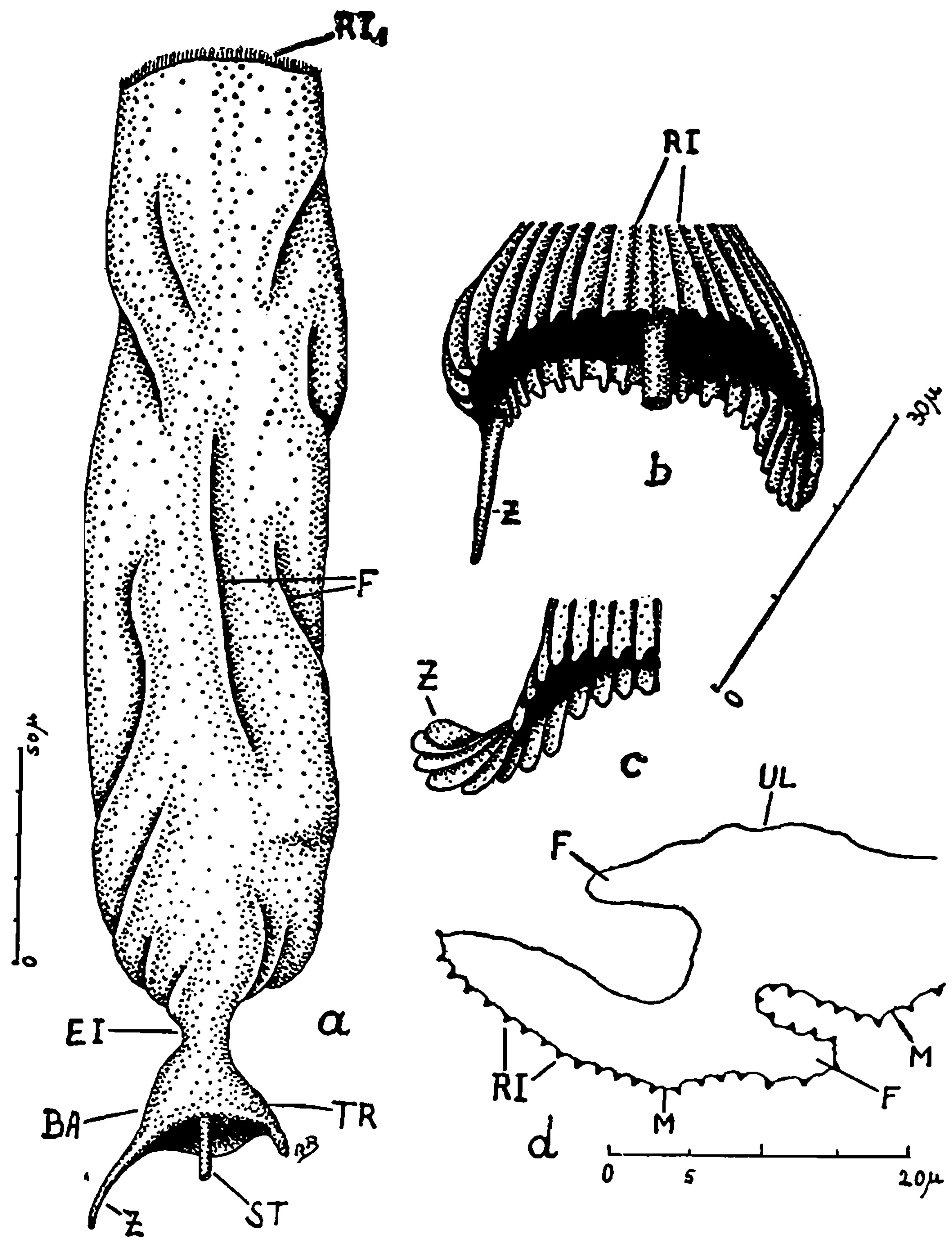

Fig. 3

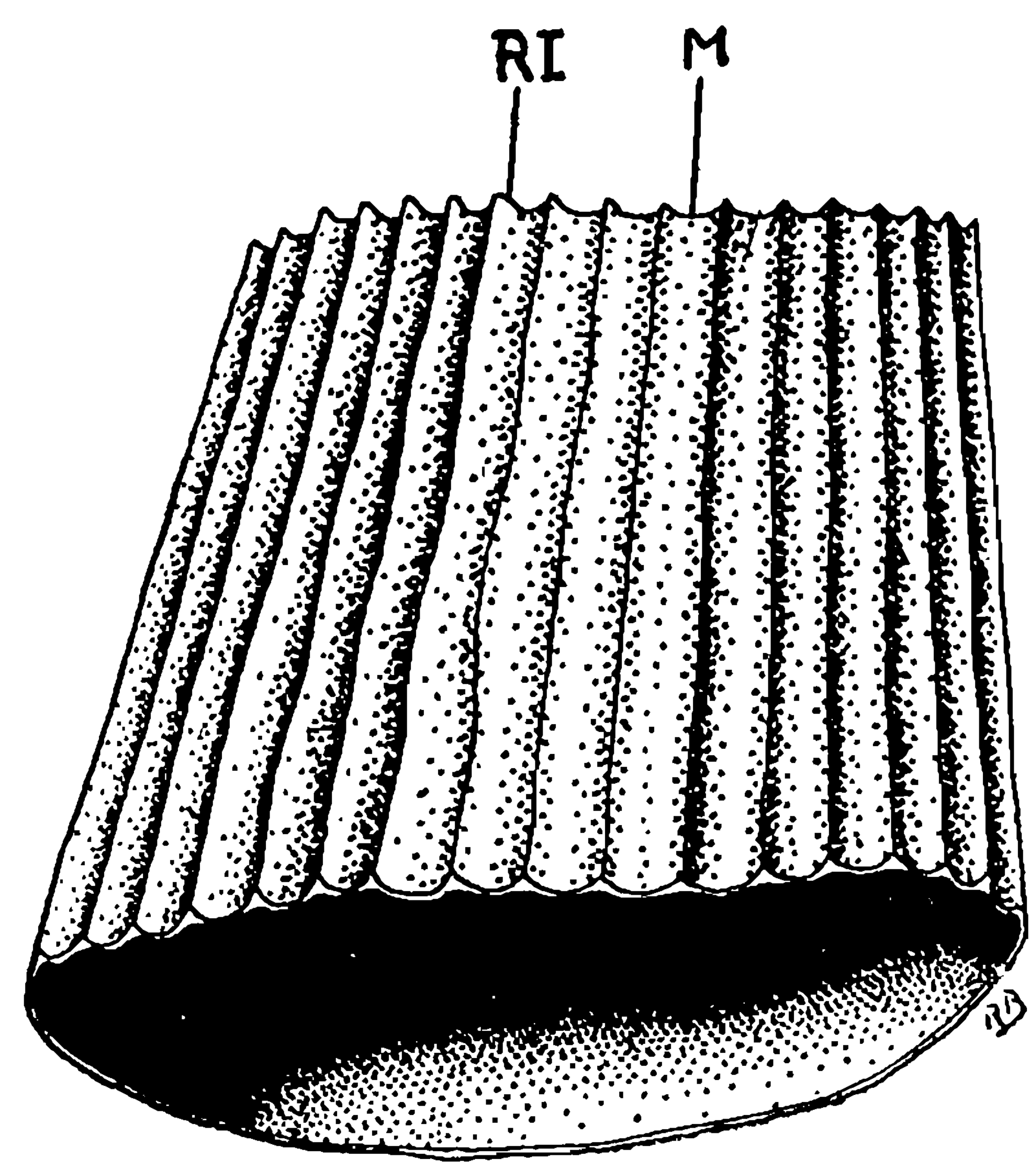

Fig. 4 
Fig. 5: Cristal da secreção aromática ainda crescendo. Têm que juntar os pontos $\mathrm{AA}, \mathrm{BB}$ e CC. Observação na luz polarisada. Aumento 1000 vêzes.

Abb. 5: Noch wachsender Kristall aus dem Duftsekret. Die Punkte AA, BB und CC sind an einander zu setzen. Beobachtet im polarisierten Licht. Vergroesserung 1000 fach. 
Mem. Inst. Oswaldo Cruz

Tomo 51, 1953

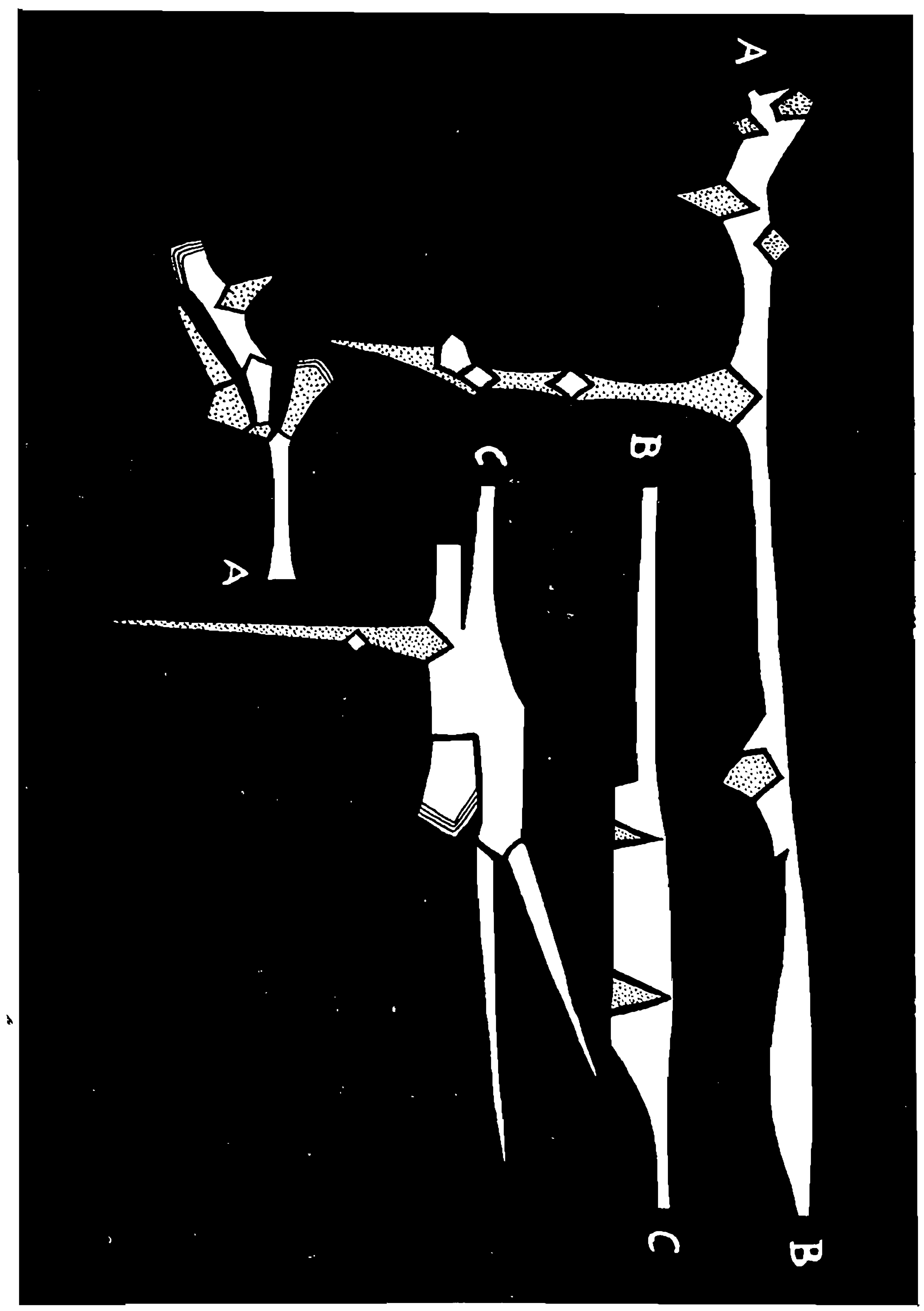

Figr. 5 
Fig. 6: Aparelho auxiliar para evaporação da secreção. Pontilhado: área cuticular nua. $A n_{1}$ : nervura anal da asa posterior, BOR: anel de cerdas.

Fig. 7: As 4 filas das cerdas do aparelho auxiliar em fig. 6 fortemente aumentadas. BO: cerdas.

Abb. 6: Hilfsapparat zur Verdunstung des Sekrets. Punktiert: nackte Hautstelle. An : 1. Analis des Hinterfluegels, BOR: Borstenring.

Abb. 7: Die 4 Borstenreihen des Hilfsapparates aus Abb. 6 staerker vergroessert. BO: Borsten. 
Mem. Inst. Oswaldo Cruz

Tomo 51, 1953
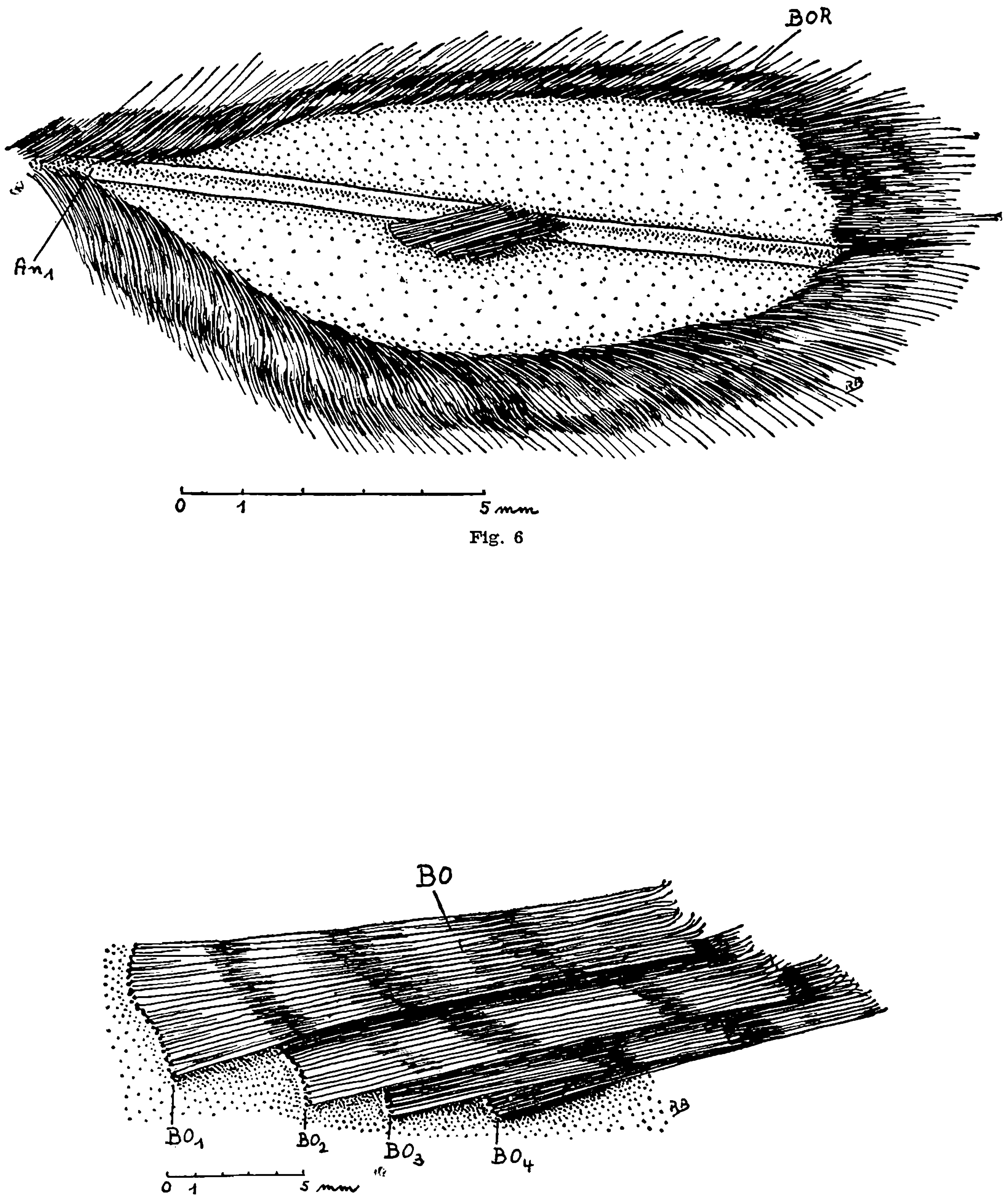

Fig. 7 
Fig. 8: Célula glandular da placa glandular do quarto segmento abdominal no corte transversal com inserção da escama odorífera. Fixação no vácuo com Fleming, grossura do corte 5 micra, coloração com hematoxilina férrica de Heidenhain - vermelho de congo - orange. BM: membrana basal, BZ: célula do anel basal, CK: cone quitinoso, DS: escama odorífera, ER: ergastoplasma, I: lume da inserção, $\mathrm{K}$ : depósito de material, $\mathrm{KE}$ : núcleo glandular, $\mathrm{KU}$ : aumento vesicular, PL: plastósomos, RO: túbulo quitinoso, SF: figura com raios. ST: pedúnculo, TR : aumento em forma de funil.

Abb. 8: Druesenzelle der Druesenplatte des 4. Abdominalsegments im Querschnitt mit Insertion der Duftschuppe. Fixierung im Unterdruck mit gorot-Orange. BM: Basalmembran, BZ: Basalringzelle, CK: Chitinkegel, DS: Duftschuppe, ER: Ergastoplasma. I: Insertionsraum, IB: Insertionsbecher, $\mathrm{K}$ : Materialeinlagerung, $\mathrm{KE}$ : Druesenzellkern, $\mathrm{KZ}$ : Kugelfoermige Erweiterung, $\mathrm{PL}$ : Plastosomen, RO: Chitinroehrchen, SF: Strahlenfigur, ST: Stiel, TR: Trichterfoermige Erweiterung. 
Mem. Inst. Oswaldo Cruz

Tomo 51, 1953

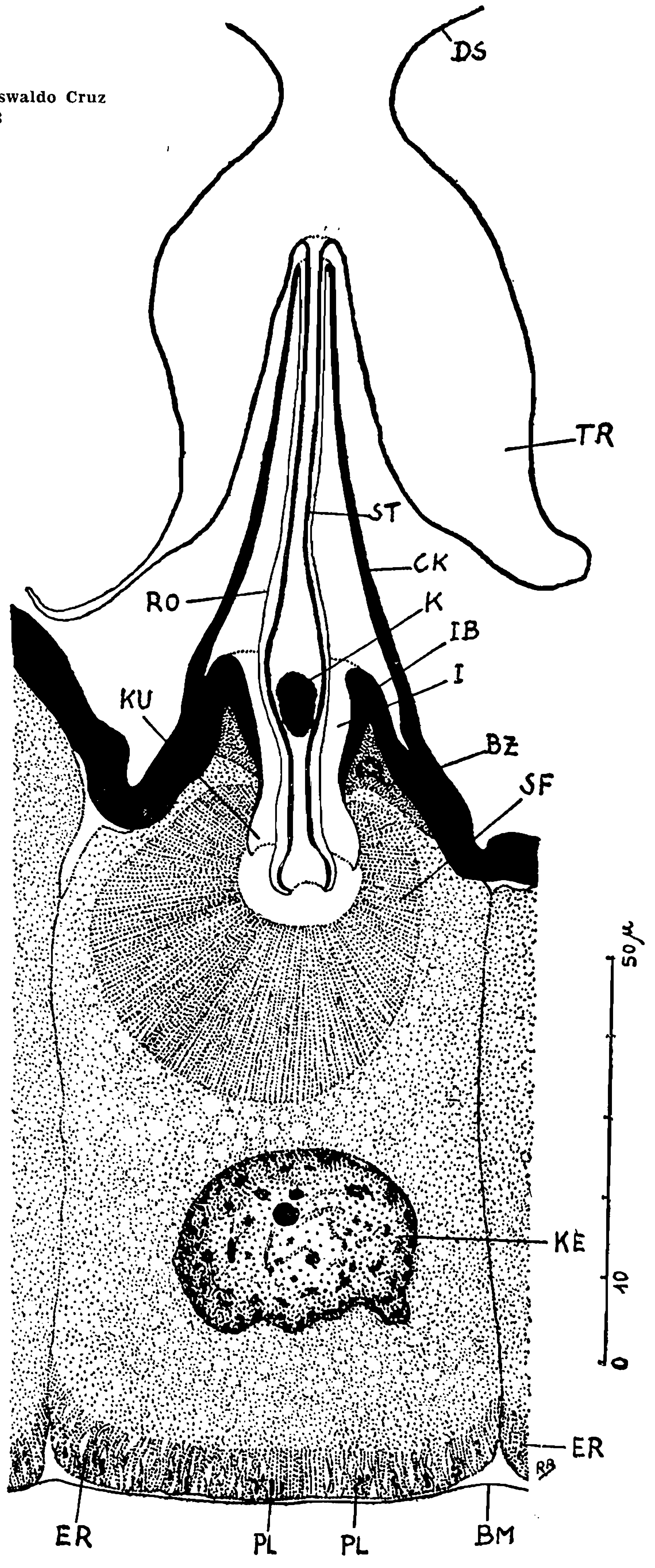

Fig. 8 